\title{
Gender differences in classroom experiences impacting self-efficacy in an AP Physics 1 classroom
}

\author{
Marta R. Stoeckel『 and Gillian H. Roehrig $\odot$ \\ University of Minnesota, St. Paul, Minnesota 55108, USA
}

(Received 8 February 2021; accepted 28 June 2021; published 12 July 2021)

\begin{abstract}
Women are underrepresented at multiple levels of physics education. One avenue for understanding the classroom experiences that perpetuate underrepresentation is physics identity, defined using the three dimensions of recognition, performance, and competence. Existing literature suggests that women tend to have a much weaker physics identity than men and that women tend to report a lower sense of competence in the form of self-efficacy than their male peers. This study examined confidence and self-efficacy as an aspect of physics identity in an AP Physics 1 class using a mixed-methods, sequential explanatory design. The quantitative data consisted of students' actual and predicted scores on in-class assessments, which showed no statistically significant difference in the accuracy of students' self-assessments by race or gender. To identify classroom activities that impacted self-efficacy, we collected responses to an openended prompt and conducted student interviews. Labs emerged as having both a positive and a negative impact on self-efficacy on many students, regardless of race or gender and male students were more likely to discuss peer-to-peer interactions as a source of self-efficacy. Boys also described figuring out how to apply concepts from labs to problem sets as an experience that contributed to their self-efficacy, while the only girl who mentioned problem sets described them as a negative experience. When describing evidence their teacher believed they are good at physics, boys focused on assessments where they had high scores, while girls focused on the feedback on assessments where they had low scores.
\end{abstract}

DOI: 10.1103/PhysRevPhysEducRes.17.020102

\section{INTRODUCTION}

Physics is a firmly male-dominated field, with women underrepresented not only among professional physicists, but at all levels of physics education. For example, the College Board reports that on the 2018 AP Physics 1 exam, less than $40 \%$ of the students taking the exam were girls [1]. And in 2017, only $21 \%$ of bachelor's degrees and $20 \%$ of doctoral degrees in physics went to women and women were only $16 \%$ of physics faculty [2].

Science identity, and physics identity more specifically, provides a powerful framework for understanding students' experiences and their intentions to persist within a science field [3-7]. Identity can be described as whether an individual sees themselves as a certain kind of person [8], so someone with a science identity sees themselves as the kind of person who does science. In a large-scale survey, Hazari et al. [6] found that a student's sense of physics identity strongly correlates to their intention to persist in the field and college women, especially women of color, majoring in physics tend to report a weaker physics

Published by the American Physical Society under the terms of the Creative Commons Attribution 4.0 International license. Further distribution of this work must maintain attribution to the author(s) and the published article's title, journal citation, and DOI. identity than men, even among students majoring in a field closely related to physics [6].

Carlone and Johnson [5] suggest science identity comprises the dimensions of competence, recognition, and performance [5]. Each of these dimensions are influenced by both internal and external factors. Performance refers to the ways in which an individual is able to demonstrate competence in line with the norms of the field, such as their fluency in the language of science or the ways they interact with others [5]. Recognition refers to the extent to which the individual is viewed as a "science person" both by themselves and by others, including classmates, instructors, supervisors, and even those outside of the scientific field. Competence is the extent to which someone demonstrates skills and knowledge valued in the field; in educational settings, test scores and grades can be viewed as a measure of competence. Students' beliefs about their ability to understand physics are also an important aspect of competence [9]. The beliefs central to competence include selfefficacy, which describes an individual's belief in their capacity to succeed [10], and confidence, which describes an individual's perceptions of their achievement [11].

Students' classroom experiences can impact their science identity development across all three dimensions [4,12]. An important aspect of competence is self-efficacy and there is substantial evidence that women in introductory physics classes tend to have a lower sense of self-efficacy than their male peers [13-18]. Mujtaba and Reiss [17] and Marshman 
et al. [14] found these gender differences in self-efficacy persist even between men and women with similar levels of academic performance.

Several studies found self-efficacy decreased for both men and women during an introductory physics course $[15,18]$, however in one study women reported experiencing states of low self-efficacy during classroom activities more often than men and exhibit greater declines in selfefficacy by the end of the course than their male peers [18]. Also, women shifted toward a more fixed mindset [19] view of physics, suggesting they developed a picture of physics identity as something innate, similar to Gee's natural identities [8], rather than as something that could be cultivated and developed. A growth mindset also tends to be correlated with a high sense of self-efficacy since it suggests the student believes they can improve through factors in their control, such as effort [19].

Jurik and colleagues examined how self-efficacy impacts the ways students engage in the classroom [13]. They found that students with a higher sense of self-efficacy were more likely than their peers to verbally engage in the classroom, regardless of their gender. This suggests that development of a strong sense of self-efficacy can have important impacts on the ways that students behave in the classroom, as well as the kind of classroom culture that develops. These studies suggest that it is important to examine the interplay between students' experiences in the classroom and the development of their sense of self-efficacy.

Confidence is closely related to self-efficacy and is often a precursor to a sense of self-efficacy [11]. Confidence describes students' perceptions of their achievement, rather than a more general sense of whether they are capable of success. While confidence can also contribute to the competence dimension of physics identity [5], it has not been examined as closely in physics classrooms as selfefficacy.

This study examines the impact of classroom experiences in high school physics on self-efficacy and confidence. Specifically, this study addressed three research questions: 1. In what ways do girls experience confidence in a physics classroom differently than boys? 2 . What kinds of classroom experiences do students see as particularly important in developing confidence and self-efficacy? 3. In what ways do girls experience opportunities to develop confidence and self-efficacy differently than boys?

\section{STUDY}

\section{A. Context}

All data were collected in the AP Physics 1 classroom at a suburban high school with approximately 1600 students. $36 \%$ of the students in the course were girls and $31 \%$ of the students in the course were identified as Black, Indigenous, or people of color (BIPOC), while 56\% of the overall school population were BIPOC. AP Physics 1 is offered as an elective and is primarily taken by high-achieving students in their senior year. Students' only prior physics experience is typically a one trimester survey of basic physics required as part of the 9th grade science sequence. The only prerequisite for AP Physics 1 at the school is students must be enrolled in or have completed precalculus. The curriculum is adapted from the Modeling Instruction [20] physics curriculum, a reformed instructional approach that relies heavily on guided inquiry.

AP Physics 1 is the only Advanced Placement (AP) course at the school in which girls are significantly underrepresented; in AP Calculus, a course that serves students at the same grade level and with similar academic interests as AP Physics 1, 47\% of the students enrolled are girls. This suggests that girls in this school experience barriers particular to physics specifically and perhaps science in general which impact their decision to enroll in AP Physics 1.

\section{B. Research design}

This study used a mixed method approach, following a sequential explanatory design [21]. Data were collected over the course of two school years.

\section{Self-assessments and course performance data}

Participants. - The quantitative data included all students enrolled in AP Physics 1 during both years of the study. The race and gender of students was collected from the district's student records system; this places an important limitation on the study as the district uses a limited number of categories for both race and gender. As a result, this study uses two subgroups for gender: boy and girl. Another important limitation of this study arises from the limited scale of this study; during the two school years during which quantitative data was collected, a total of 92 students enrolled in AP Physics 1 at the target high school, with small sample sizes in some subgroups; Table I describes the demographics of study participants. The participant demographics were similar across the two years of data collection.

Data collection.-This study measured confidence in order to examine students' perceptions of their achievement. Data on students' confidence and their actual performance were

TABLE I. Demographics of study participants.

\begin{tabular}{lccc}
\hline \hline Race & Boys & Girls & Total \\
\hline White & 43 & 23 & 66 \\
Asian & 11 & 1 & 12 \\
Black & 6 & 4 & 10 \\
Hispanic & 2 & 1 & 3 \\
American Indian & 1 & 0 & 1 \\
Total & 63 & 29 & 92 \\
\hline \hline
\end{tabular}


collected using in-class quizzes that students completed approximately once per week. The course uses standardsbased grading, so for each standard on the quiz, students received a score on a scale of 1-5. Confidence was measured by asking students to predict the score they received on each standard on the quiz as part of a written self-assessment included at the end of each quiz.

As part of the self-assessment on the weekly quizzes, students were asked to provide a written response to the prompt "If you believe you are at mastery, what strategies or actions helped? If not, what will you do to improve?" During the second year of data collection, these qualitative responses were recorded, along with the race and gender of the student and their average score and average selfassessment. While these responses were collected throughout year 2 of the study, they were not reviewed until after an initial analysis of the quantitative data.

\section{Student interview data}

Participants.-The final data source in this study was oneon-one interviews conducted with student volunteers during the second year of the study. A total of 10 students out of 52 enrolled in the course at the time volunteered to participate in the interviews; four of those students were girls and three of the students were boys of color, roughly mirroring the overall demographics of students in the study.

Data collection.-Interviews were conducted after the AP Physics 1 exam, so that all standard course assessments were completed prior to the interviews. The interviews were conducted with student volunteers, so an important limitation is that the students who elected to participate likely had a positive relationship with the instructor and positive experiences in the course overall. Interviews were structured using open-ended questions. The interview questions are included in the Supplemental Material [22]. All of the questions were intended to probe students' sense of selfefficacy, the classroom experiences that impacted them, and their perception of a physics identity. The open-ended nature of the prompts provided insights into traits and actions the student associated with being good at physics, which can be assumed to be traits and actions the student associated with holding a physics identity, as well as the kinds of classroom experiences which had a lasting impact.

Interviews were conducted one-on-one between a student and the first author. The first author kept written notes during each interview and all interviews were recorded using an audio recorder and later transcribed. Interview transcripts included a student identifier to support the triangulation of results by comparing interview responses to students' academic performance, confidence as indicated by self-assessments, and responses to open-ended selfassessment prompts.

\section{DATA ANALYSIS}

\section{A. Quantitative analysis}

Quantitative results were analyzed using the CCL Confidence Achievement Window framework, proposed by Covington Clarkson et al. [11], for considering the relationship between student's confidence and their actual achievement. This framework, based on the Johari Window, categorizes students into four profiles as shown in Fig. 1. The public and unknown profiles represent a high calibration between confidence and achievement, with the public profile indicating a student with both high achievement and high confidence, while the unknown profile indicates low confidence and low achievement. The hidden and blind profiles both represent poor calibration between confidence and achievement. The blind profile, called underestimating here, indicates low confidence and high achievement, while the hidden profile, called overestimating here, indicates high confidence and low achievement.

We averaged the actual and predicted scores for each student over the course of the school year and used those scores to place each student onto a CCL Confidence Achievement Window. An average score above 0.75 indicated the student had ratings of "Near Mastery" or "Mastery" for most standards and demonstrated the depth of understanding necessary to pass the AP Physics 1 exam, so we selected this score as the cutoff for high achievement and high confidence. We calculated the percentage of students in each profile and compared the distributions for boys and girls using Fisher's exact test.

Since self-efficacy may shift during an introductory physics course $[15,18]$, we determined the profile distribution for each assessment, basing each students' profile only on their actual and self-assessment score for the individual assessment. The fraction of students in each profile was calculated by gender for each assessment in order to determine whether the distribution changed over the course of the school year.

\section{B. Qualitative analysis}

We reviewed the interview transcripts to determine whether particular types of classroom activities and experiences were mentioned in multiple interviews or in response to multiple interview questions. Next, we

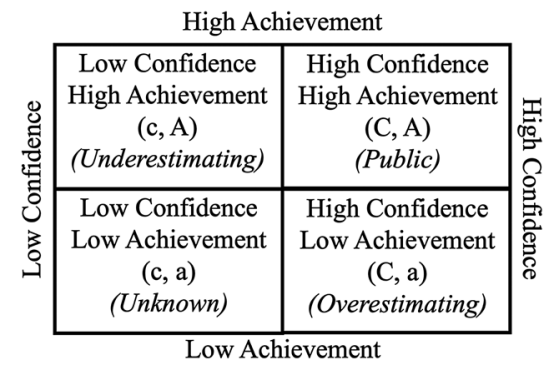

FIG. 1. CCL Confidence achievement window [11]. 
reviewed responses to the open-ended assessments to identify types of classroom activities that were mentioned by many students. In the analysis of both the interviews and the self-assessments, we also noted whether a student described an experience or activity as having a positive or negative impact on their self-efficacy. We then compared responses to the interview questions to the responses to the open-ended self-assessment prompt to look for potential connections between the kinds of activities that students identified as memorable self-efficacy experiences in the interviews and the kinds of activities students described most valuable for their learning on their self-assessments.

\section{RESULTS}

\section{A. Quantitative self-assessments}

Figure 2 shows a plot of students in a CCL Confidence Achievement Window identified by gender and Table II shows a distribution of students across each profile by gender. A Fisher's exact test produced a $p$ value of 0.91 , indicating there is no statistically significant difference in the distribution of boys and girls across the profiles, suggesting that students in the study demonstrated similar levels of confidence and achievement, regardless of their gender.

$53 \%$ of students fell into the public profile and $26 \%$ of students fell into the unknown profile, indicating that most students had good calibration of their confidence. $13 \%$ of students fit the underestimating profile and $8 \%$ fit the overestimating profile, indicating under confidence was slightly more prevalent than overconfidence among students in this study.

To examine whether the distribution of students in each profile changed over the course of the year, the authors determined the fraction of students by gender in each profile each standard. These results are shown in the Supplemental Material [22]. In general, during year 2, more students fit the underestimating and public profiles indicating higher achievement than in year 1. This is likely because year 1 of the study coincided with the first year AP Physics 1 was offered in the district, resulting in curriculum

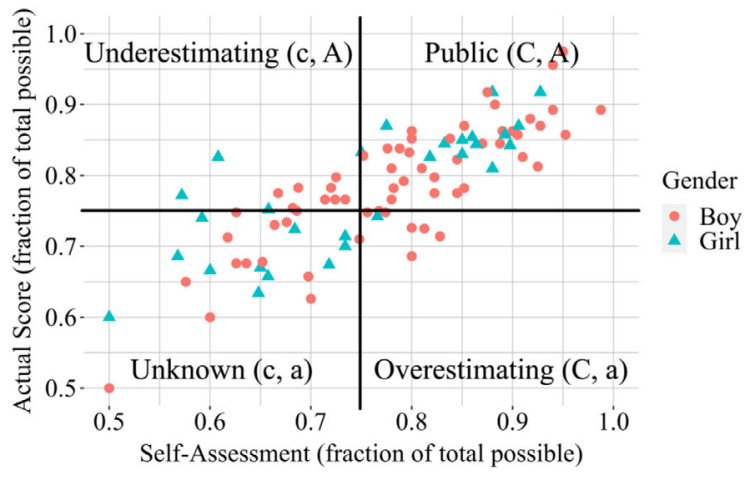

FIG. 2. CCL Confidence achievement window by gender.
TABLE II. Percent of population in profile by gender.

\begin{tabular}{lcc}
\hline \hline Profile & Boys $(n=63)$ & Girls $(n=29)$ \\
\hline Underestimating (c, A) & $14.29 \%$ & $10.34 \%$ \\
Public (C, A) & $55.56 \%$ & $48.28 \%$ \\
Unknown (c, a) & $20.63 \%$ & $37.93 \%$ \\
Overestimating (C, a) & $9.52 \%$ & $37.93 \%$ \\
\hline \hline
\end{tabular}

revisions between years 1 and 2 of the data collection when the course materials were refined to better align to the AP Physics 1 exam. One impact of these revisions is the sequence of content and the skills emphasized in some standards changed between years 1 and 2 of this study. In both years, there was no clear pattern in the fraction of students fitting each profile as the year progressed, indicating that there was not a clear change in student confidence as the course progressed in this study.

There were several topics that produced similar results in both years. First, in both years, large fractions of students fit the public profile, representing high confidence and high achievement, on the standards for constant velocity representations, projectile motion representations, balanced forces, and energy bar charts. Second, on the standards for Kirchoff's laws and the standards associated with rotation, a relatively large proportion of students fit profiles associated with low confidence, with more girls than boys fitting this profile in year 2 .

\section{B. Qualitative self-assessments and student interviews}

The open-ended self-assessment prompt and student interviews revealed four major experiences which students perceived as important for their confidence: lab activities, problem sets, peer interactions, and assessment feedback. Sample, illustrative quotes are included to provide rich information for the reader using student voices. A table of additional quotes providing evidence for these themes can be found in the Supplemental Material [22].

\section{Lab activities}

In both the interviews and the self-assessments, students consistently identified labs as having a positive effect on their self-efficacy and confidence. In this classroom, most topics were introduced through a guided inquiry lab known as a paradigm lab [20]. Students participated in a wholeclass discussion to establish a guiding question, then worked in small groups to determine a procedure and collect data. Students then shared their results in a whole class discussion to identify key results. The teacher concluded these labs with a brief lecture connecting students' results to the target physics concepts.

On the open-ended self-assessments, it was common for students to identify labs as helpful. The student interviews provided additional insights into the role of labs in students' self-efficacy. Students saw guided inquiry and 
labs they perceived as connected to the real world as especially important to their self-efficacy.

Guided inquiry.-Several students referenced the guided inquiry labs typically used to start a unit in Modeling Instruction [20], attributing their self-efficacy to their experiences discovering new concepts. For example, one girl described these labs as a source of science identity when asked about activities that made her feel good at physics:

I think the self-discovery thing, like when you figure it out yourself, that's, like, always really good. Cause it makes you feel like you're doing it yourself and you're, like, this scientist that knows everything.

While most of the students interviewed expressed a similar sense of ownership from discovery learning as a contributor to their self-efficacy, the open-ended nature of the guided inquiry labs also had a negative impact on some students' sense of self-efficacy. During the interviews, several students mentioned labs as both a catalyst and an impediment to their sense of self-efficacy. One student who saw the hands-on nature of labs as making him feel good at physics also described his discomfort with the limited instruction inherent in these labs when asked about activities that made him feel not very good at physics:

I'm very much a learner and worker who does well under instruction, so when I'm left to my own devices, it's more difficult for me to understand the concepts and stuff and lessons. So I would say in physics when I'm left to do a lab by myself, I don't tend to do as well.

These contrasting responses to guided inquiry labs, especially when both perspectives were expressed by the same student, suggest it is important to build a classroom culture and provide instructional scaffolds designed to help students manage their discomfort with the limited teacher direction during these activities.

Many of the students interviewed also had very specific memories of particular labs from very early in the year. When asked for a specific moment when she felt good at physics, one girl described her experience during a lab from the first day of the course:

It was the first lab we did, the buggy lab, that one. Like, all the numbers were just like fitting together and it was, it was like we were actually applying something from math and put, like, physics in the real world and the numbers were just coming together and clicking and I was just like, 'I love physics, I'm gonna be so good at this!'

This student's use of language about the content of the lab "coming together" or "clicking" was fairly common among students who referenced specific labs that contributed to their self-efficacy. This suggests the experience of developing a new idea prior to formal instruction over the topic helped students to feel a sense of self-efficacy.

All of the students who referenced a specific classroom activity as helping their sense of self-efficacy referenced something from the first half of the course, even among students who had higher achievement during the second half of the course. This suggests that early experiences in the course laid an important foundation for students' selfefficacy.

Real-world labs.-The sensation of seeing physics in the real world described by the girl who recalled the buggy lab also appeared to be important. Several other students emphasized the importance of directly seeing and experiencing physics in the lab as something that helped build their sense of self-efficacy. As one girl explained:

It's like labs and being able to see stuff actually happen because sometimes it's hard to learn for me when we're doing, like, alphabet soup problems [problems with literal equations] or something like that. So I feel like when I'm actually able to see it that's really helpful because sometimes it can be a little confusing.

Several standards included labs using web-based simulations or commercially recorded video. It was less common for students to reference these labs in their responses to the open-ended self-assessment prompts. In the interviews, several students described these labs as an experience where they felt low self-efficacy. When asked about a time he did not feel good at physics, one of the boys of color interviewed quickly named the unit on circuits and described the unit's heavy reliance on a simulation as an important factor:

It was hard for me to understand and wrap my head around and I feel like it's because we had this simulation and I was able to learn off that, but it was on a computer and I feel like it was cuz I never was actually able to see it and touch it.

The lack of self-efficacy students felt around circuits and other topics with computer-based labs suggests that the opportunity to manipulate equipment directly is important for students to develop a sense of self-efficacy. This is also reflected in the quantitative self-assessments where a high proportion of students, especially girls, fit the unknown profile with low achievement and low confidence on the standard for Kirchoff's laws in both years. In both years of the study, instruction relied heavily on a simulation, rather than real-world labs. While students did not discuss rotation during the interviews, the labs for these topics relied on video-based virtual labs and a relatively large fraction of students fit the profiles associated with low 
confidence on these topics, again reinforcing that it was difficult for students to build self-efficacy in topics with purely digital labs.

By contrast, students had relatively high confidence on the standards for constant velocity representations, balanced force representations, and energy bar charts. The labs for all of these topics utilized low-tech equipment such as meter sticks, stopwatches, and spring scales that are familiar to students and provide very direct, tactile experiences with the quantities being measured. Students also had relatively high confidence on the standard on projectile motion representations. While this topic was introduced through video analysis, students recorded their own videos and manually tracked the object of interest, which likely helped students connect the video analysis to their direct experience.

\section{Problem sets}

On the written self-assessments, problem sets were another common activity students considered important to their self-efficacy. As is typical in Modeling Instruction [20], problem sets emphasized students applying concepts they had developed during lab activities. Students worked on these problem sets in small groups with minimal prior instruction. In the interviews, students, especially boys, discussed particular aspects of problem sets that were important to their self-efficacy. Several boys saw the process of figuring out how to apply what they figured out in a lab to the written problems as important to their self-efficacy. One boy described his perception of this process when asked about the kinds of activities that make him feel good at physics:

I think when, not like the lab, but after a lab that we do. So, like, we do a lab that hammers at the different ways that physics works and we get a problem set, like, the day after. That it's the same-they're not the same thing, but it's like the same concept. And then it's like I semiunderstand what we did yesterday and then we practice it and all the sudden, I just really understand the problems.

Several boys also recalled a specific problem they had been successful at connecting to the previous day's lab. As with students who recalled specific labs, students who referenced specific problems consistently spoke only about problems from early portions of the course, suggesting again these early experiences were important to students' self-efficacy.

By contrast, only one girl talked about the transition from labs to written problems and, by contrast, interpreted the challenge of this experience as evidence she is not good at physics:

Some of the worksheets were...rough cause, you know, you do an experiment and you can see the physics and sometimes with the worksheets you look at it and it's like you can almost grasp it, but I don't know what is happening here.

Similar to the students who saw guided-inquiry labs as a barrier to self-efficacy, this student interpreted the ambiguity and confusion she experienced on problems as evidence she is not good at physics, rather than as an expected part of the process.

\section{Peer interactions}

Several of the boys interviewed talked about interactions with their peers while working problems as an experience that positively affected their self-efficacy. They described experiences where peers asked them for help or took their contributions seriously during small group discussions, pointing to these experiences both as moments that helped them feel good at physics and as evidence that their peers believe they are good at physics, such as the boy quoted here:

They think I'm okay and I know that cause maybe when they ask for your ideas like 'okay, what do you think about this?' giving the chance to tell them 'I think we should do this or do that' and also when they do listen to you with the suggestion it, means they're like 'okay, it's probably right',

Interestingly, the only female student who brought up her peers asking her questions or soliciting her ideas believed that her peers overestimated her physics ability:

I think it's one of those things where I'm, like, generally, a smart person, so they'd like just assume that I kinda know what I'm doing, but, like, they're all super good at physics so I think...I think they overestimate my abilities almost.

\section{Assessment feedback}

During the interviews, feedback students received on assessments emerged as an additional experience that impacted their self-efficacy. Feedback was not mentioned by any students on the written self-assessments, but this is likely because the written self-assessments were only collected for students' first attempt on each standard, so they had not received or used written feedback from the instructor on that skill. During the interviews, when asked whether their instructor believes they are good at physics, a number of students, especially boys, referred to the comments and grade on a quiz they had done well on. The boys interviewed typically focused on quizzes where they had done well, such as the boy quoted here:

Yeah, cause, if I have a good grade in the class and the teacher is the same teacher that marked it, so obviously the teacher would agree that I'm good in that class. 
This response suggests boys saw demonstrating competence and external recognition as related.

Interestingly, several students, especially girls, focused on the kind of feedback the instructor wrote on assessments they had done poorly on as evidence their teacher believed they are good at physics. As one girls put it:

Whenever we take quizzes and your give the quizzes back to us, you would write feedback on them and it was never anything like bad. It was always constructive and it was always helpful.

This suggests that some of the students interviewed experienced external recognition even when they do not demonstrate competence if the recognition is framed as a belief in the students' ability to improve. It is worth note that every girl interviewed expressed this view, while the boys who focused on feedback from their teacher were in the minority.

\section{LIMITATIONS}

This study has several important limitations. First, while the intersections of race, gender, and other identities have important and unique impacts on the development of a student's sense of science identity [3-6], the very small number of BIPOC girls enrolled in AP Physics 1 at this high school preclude a meaningful consideration of the intersections of race and gender in this study. In addition, this study relied on a gender binary since the high school only reported gender as male or female in student records. It is also important that all of the students interviewed were volunteers, meaning that students who had positive experiences in the course were likely overrepresented in the interviews.

This study also relied on students' memories and perceptions of their experiences in the class, which may not reflect what actually occurred in the classroom. For example, it is not clear whether the boys interviewed said more about peers asking them questions and listening to their ideas because they had more of those experiences than girls or because the girls interviewed interpreted those experiences differently, such as the student who thought her group overestimated her.

\section{DISCUSSION AND CONCLUSIONS}

This study found that both boys and girls not only had similar levels of confidence, but had confidence that was well calibrated to their actual achievement. Since confidence is typically a precursor for self-efficacy [11], this result stands in contrast with existing literature that found men had a higher sense of self-efficacy than women [1318]. Since this study did not directly examine self-efficacy, it is possible that while gender did not predict a students' confidence, gender may have played a role in how confidence developed into self-efficacy.
These results do not show a clear decline in the proportion of students in profiles associated with low confidence, a contrast with previous studies that found college students' self-efficacy declined during an introductory course $[15,18]$. Rather, the distribution of students across profiles fluctuated throughout each year of data collection, suggesting students did not have a clear increase or decrease in confidence as the course progressed. While this may suggest the participants in this study did not experience the decline in self-efficacy seen in other studies, it is also possible that the relationship between confidence and self-efficacy shifted for students over the course of the school year.

These results raise the question of what classroom experiences contributed to students' perceptions. In interviews, students referenced clear, specific memories of early experiences in the classroom that helped to shape their beliefs about their abilities in physics, suggesting that experiences early in the course played an important role in developing students' sense of self-efficacy. It is therefore particularly crucial to ensure students have experiences such as learning new concepts through guided inquiry that will contribute to self-efficacy early in the school year to provide a foundation for students' physics identity.

Sense-making activities, especially guided inquiry labs and problem sets, played an important role for both boys and girls in not only developing a sense of self-efficacy, but in developing a physics identity as a whole. Both boys and girls reported experiencing competence by figuring out new concepts in the lab, which led to a sense of self-efficacy. Boys also reported experiencing competence and selfefficacy when figuring out how to apply concepts from the lab to problems. The interviews suggest students also saw guided-inquiry labs as an opportunity to engage in the performance dimension and act like a scientist, contributing to a robust science identity in addition to a sense of selfefficacy. This mirrors Carlone's observations of girls in a physics classroom using a reformed curriculum [4]. Much like Modeling Instruction, the classroom observed by Carlone placed science as a process, rather than a set of facts, and emphasized students' ideas and questions throughout the curriculum [4]. This provided ample opportunity to engage in the performance dimension, leading some girls to develop a robust physics identity. In this study, guided inquiry labs in particular appear to have played a similar role in giving students the opportunity to see themselves as physicists.

There was, however, some tension in the ways students in this study experienced guided inquiry and problem sets. Even some of the students who saw guided-inquiry as important to their self-efficacy interpreted the confusion, mistakes, and ambiguity inherent in guided inquiry in ways that harmed their self-efficacy. In addition, only boys saw problem sets as contributing to their self-efficacy. The only girl who discussed the problems described similar 
frustrations to the ones students described during guidedinquiry, which hurt her self-efficacy. For girls in particular, these challenges may be actively threatening to their identity as a good student [4]. Girls often associate being a good student with behaviors like following directions, paying attention, and getting correct answers that are devalued during sense-making activities in approaches such as Modeling Instruction [20], which can lead to students feeling frustrated and potentially rejecting a science identity. To minimize the negative self-efficacy impacts of sense-making activities, it is therefore crucial to normalize working through confusion and mistakes, reframing them as skills such as troubleshooting and solving problems. It is also important to recognize that asking students to engage productively in guided inquiry, problem sets with minimal instruction, and other reformed approaches involves attending to students' identity development and the behaviors they connect to their student identity [4].

Finally, students viewed labs they perceived as connected to the real world as especially important to their self-efficacy and confidence. In interviews, students saw arriving at new physics knowledge from a phenomenon they had directly observed and measured as a powerful experience that was important in developing a sense of selfefficacy. Students also described struggling to develop selfefficacy on topics where labs were primarily conducted using simulations or video since students saw these labs as less connected to the real world. It is therefore important when using digital labs to find ways to support students in drawing connections to the real world in order to support the development of student self-efficacy.

Identity formation is a social process [23], so it is no surprise that students saw peer interactions as important to their sense of self-efficacy. It is not, however, clear why boys in this study consistently described peer interactions that supported their self-efficacy, while the only girl to describe similar interactions saw them as evidence she was fooling her peers, rather than an experience that contributed to her self-efficacy. Jovanovic and King [24] and Wieselmann et al. [25] both observed that in mixed-gender groups, girls' ideas were often quickly dismissed by boys in the group, so it is possible that girls in this study had fewer experiences than boys where peers listened to their input. Wieselmann et al. [25] and Quinn et al. [26] also observed that during highly structured activities, student participation was more equitable, though students were less likely to engage in behaviors that promote the development of a science identity. This suggests that it could be valuable to provide structures to group-work, such as roles, during otherwise open-ended activities to promote equitable participation and ensure that all students have the opportunity to experience positive recognition from their peers.

It is also possible that girls experienced positive peer recognition, but interpreted those experiences differently than boys in the study. Patrick and Yoon [27], in their observations of a group of eighth-grade students, found boys in the group tended to use their contributions to demonstrate competence to their peers, which suggests they may have been actively seeking external recognition from peers in the group. The girls observed, by contrast, appeared to be motivated by seeking understanding or wanting to appear conscientious through their contributions. If similar motivations were present in this study, it is possible girls were attending to peer recognition differently than boys.

In this study, girls viewed feedback on assessments where they scored poorly as evidence the teacher believed they are good at physics. This suggests that not only were students able to experience external recognition without experiencing competence, but the recognition and growth mindset messages in the feedback were more impactful than experiencing low competence. While recognition, competence, and performance are all important to a physics identity [5], students do not need to experience all three at once and a positive experience in one dimension may be more impactful than a simultaneous negative experience in another. The ability of girls in this study to separate recognition and competence was rooted in a growth mindset [19] since girls emphasized the feedback was evidence the teacher believed they could improve. This interpretation was likely influenced by growth mindset messages present in the classroom beyond the teacher feedback, such as a policy allowing retakes [28].

Students take messages about who is good at physics and what it means to be good at physics from their experiences in the classroom. These messages impact their confidence, self-efficacy, and their sense of physics identity as a whole. Understanding the messages students hear and how they impact students' beliefs about their abilities is a stepping stone to designing classrooms where every student can see themselves as the kind of person who does physics. 
[1] College Board, 2018 National Report (College Board, Reston, VA, 2018), https://research.collegeboard.org/ programs/ap/data/participation/ap-2018.

[2] A. Porter and R. Ivie, Women in Physics and Astronomy, 2019 (American Physical Society, College Park, MD, 2019), https://www.aip.org/sites/default/files/statistics/women/ Women\%20in\%20Physics\%20and\%20Astronomy\% 202019.1.pdf.

[3] N. W. Brickhouse, P. Lowery, and K. Schultze, What kind of girl does science? The construction of school science identities, J. Res. Sci. Teach. 37, 5 (2000).

[4] H. B. Carlone, The cultural production of science in reform-based physics: Girls' access, participation, and resistance, J. Res. Sci. Teach. 41, 392 (2004).

[5] H. B. Carlone and A. Johnson, Understanding the science experiences of successful women of color: Science identity as an analytic lens, J. Res. Sci. Teach. 44, 1187 (2007).

[6] Z. Hazari, P. M. Sadler, and G. Sonnert, The science identity of college students: Exploring the intersection of gender, race, and ethnicity, J. Coll. Sci. Teach. 42, 5 (2013).

[7] Z. Hazari, G. Sonnert, P. M. Sadler, and M. C. Shanahan. Connecting high school physics experiences, outcome expectations, physics identity, and physics career choice: A gender study, J. Res. Sci. Teach. 47, 8 (2010).

[8] J. P. Gee, Chapter 3: Identity as an analytic lens for research in education, Rev. Res. Educ. 25, 99 (2000).

[9] Z. Y. Kalender, E. M. Marshman, C. Schunn, T. NokesMalach, and C. Singh, Why female science, technology, and mathematics majors do not identify with physics: They do not think others see them that way, Phys. Rev. Phys. Educ. Res. 15, 020148 (2019).

[10] A. Bandura, Self-efficacy: Toward a unifying theory of behavioral change, Psychol. Rev. 84, 191 (1977).

[11] L. M. Covington Clarkson, Q. U. Love, and F. D. Ntow, How confidence relates to mathematics achievement: A new framework, in Proceeding of the 9th International Conferences of Mathematics Education and Society in Volos, Greece (2017), https://www.mescommunity.info/ mes9b.pdf.

[12] H. B. Carlone, (Re)producing good science students: Girls' participation in high school physics, J. Women Minorities Sci. Eng. 9, 17 (2003).

[13] V. Jurick, A. Gröschner, and T. Seidel, How student characteristics affect girls' and boys' verbal engagement in physics instruction, Learn. Instr. 23, 33 (2013).

[14] E. M. Marshman, Z. Y. Kalender, T. Nokes-Malach, C. Schunn, and C. Singh, Female students with A's have similar physics self-efficacy as male students with C's in introductory course: A cause for alarm?, Phys. Rev. Phys. Educ. Res. 14, 020123 (2018).

[15] E. M. Marshman, Z. Y. Kalender, C. Schunn, T. NokesMalach, and C. Singh, A longitudinal analysis of students' motivational characteristics in introductory physics courses: Gender differences, Can. J. Phys. 96, 391 (2018).

[16] T. Mujtaba and M. J. Reiss, Inequality in experiences of physics education: Secondary school girls' and boys' perceptions of their physics education and intentions to continue with physics after the age of 16, Int. J. Sci. Educ. 35, 1824 (2013).

[17] T. Mujtaba and M. J. Reiss, What sort of girl wants to study physics after the age of 16 ? Findings from a large-scale UK survey, Int. J. Sci. Educ. 35, 2979 (2013).

[18] J. M. Nissen and J. T. Shemwell, Gender, experience, and self-efficacy in introductory physics, Phys. Rev. Phys. Educ. Res. 12, 020105 (2016).

[19] C.S. Dweck, Mindset: The New Psychology of Success (Random House, New York, 2008).

[20] J. Jackson, L. Dukerich, and D. Hestenes, Modeling instruction: An effective model for science education, Sci. Educat. 17, 1 (2008).

[21] J. W. Cresswell, V. L. Plano Clark, M. L. Gutmann, and W. E. Hanson, Advanced mixed methods research designs, in Handbook on Mixed Methods in the Behavioral and Social Sciences (Sage Publications, New York, 2003).

[22] See Supplemental Material at http://link.aps.org/ supplemental/10.1103/PhysRevPhysEducRes.17.020102 for a sample self-assessment, interview questions, a table of profile distributions for each standard assessed during the study, and additional quotes from student interviews.

[23] N. W. Brickhouse, Embodying science: A feminist perspective on learning, J. Res. Sci. Teach. 38, 3 (2001).

[24] J. Jovanic and S. King, Boys and girls in the performancebased classroom: Who's doing the performing?, Am. Educ. Res. J. 35, 3 (1998).

[25] J. R. Wieselmann, E. A. Dare, E. A. Ring-Whalen, and G. H. Roehrig, "I just do what the boys tell me": Exploring small group student interactions in an integrated STEM unit, J. Res. Sci. Teach. 57, 112 (2019).

[26] K. Quinn, M. Kelley, K. McGill, E. Smith, Z. Whipps, and N. Holmes, Group roles in unstructured labs show inequitable gender divide, Phys. Rev. Phys. Educ. Res. 16, 010129 (2020).

[27] H. Patrick and C. Yoon, Early adolescents' motivation during science investigation, J. Educ. Res. 97, 319 (2004).

[28] K. L. Sun, The mindset disconnect in mathematics teaching: A qualitative analysis of classroom instruction, J. Math. Behav. 56, 100706 (2019). 